\title{
Prognostic value of metastin expression in human pancreatic
}

\section{cancer}

\author{
Kazuyuki Nagai ${ }^{1}$, Ryuichiro Doi*1, Fumihiko Katagiri², Tatsuo Ito1, \\ Atsushi Kida ${ }^{1}$, Masayuki Koizumi ${ }^{1}$, Toshihiko Masui ${ }^{1}$, Yoshiya Kawaguchi ${ }^{1}$, \\ Kenji Tomita ${ }^{3}$, Shinya Oishi ${ }^{3}$, Nobutaka Fujii ${ }^{3}$ and Shinji Uemoto ${ }^{1}$
}

\author{
Address: ${ }^{1}$ Department of Hepato-Biliary-Pancreatic Surgery and Transplantation, Kyoto University, Kyoto, Japan, ${ }^{2}$ Department of Clinical \\ Pharmacy, Oita University Hospital, Oita, Japan and ${ }^{3}$ Graduate School of Pharmaceutical Sciences, Kyoto University, Kyoto, Japan \\ Email: Kazuyuki Nagai - kaznagai@kuhp.kyoto-u.ac.jp; Ryuichiro Doi* - doir@kuhp.kyoto-u.ac.jp; Fumihiko Katagiri - fkata@med.oita-u.ac.jp; \\ Tatsuo Ito - tatsuoi@kuhp.kyoto-u.ac.jp; Atsushi Kida - kida@kuhp.kyoto-u.ac.jp; Masayuki Koizumi - makoiz@kuhp.kyoto-u.ac.jp; \\ Toshihiko Masui - tmasui@kuhp.kyoto-u.ac.jp; Yoshiya Kawaguchi -yoshiyak@kuhp.kyoto-u.ac.jp; \\ Kenji Tomita - kenjitomita@f01.mbox.media.kyoto-u.ac.jp; Shinya Oishi - soishi@pharm.kyoto-u.ac.jp; Nobutaka Fujii - nfujii@pharm.kyoto- \\ u.ac.jp; Shinji Uemoto - uemoto@kuhp.kyoto-u.ac.jp \\ * Corresponding author
}

Published: 21 January 2009

Journal of Experimental \& Clinical Cancer Research 2009, 28:9 doi:10.1 186/1756-9966-28-9

This article is available from: http://www.jeccr.com/content/28/I/9

(c) 2009 Nagai et al; licensee BioMed Central Ltd.

This is an Open Access article distributed under the terms of the Creative Commons Attribution License (http://creativecommons.org/licenses/by/2.0), which permits unrestricted use, distribution, and reproduction in any medium, provided the original work is properly cited.
Received: 4 December 2008

Accepted: 21 January 2009

\begin{abstract}
Background: KiSS-I was identified as a metastasis-suppressing gene in melanoma cells. The KiSSI gene product (metastin) was isolated from human placenta as the ligand of GPR54, a G-proteincoupled receptor. The role of metastin and GPR54 in tumor progression is not fully understood.
\end{abstract}

Methods: We investigated the clinical significance of metastin and GPR54 expression in pancreatic cancer. We evaluated immunohistochemical expression of metastin and GPR54 in pancreatic ductal adenocarcinoma tissues obtained from 53 consecutive patients who underwent resection between July 2003 and May 2007 at Kyoto University Hospital. In 23 consecutive patients, the plasma metastin level was measured before surgery by enzyme immunoassay.

Results: Strong immunohistochemical expression of metastin was detected in 13 tumors (24.5\%), while strong expression of GPR54 was detected in 30 tumors (56.6\%). Tumors that were negative for both metastin and GPR54 expression were significantly larger than tumors that were positive for either metastin or GPR54 ( $p=0.047$ ). Recurrence was less frequent in patients who had metastin-positive tumors compared with those who had metastin-negative tumors ( $38.5 \%$ versus $70.0 \%, p=0.04)$. Strong expression of metastin and GPR54 was significantly correlated with longer survival $(p=0.02)$. Metastin expression by pancreatic cancer was an independent prognostic factor for longer survival (hazard ratio, 2.1; 95\% confidence interval, I.I-4.7; $p=0.03$ ), and the patients with a high plasma metastin level $(n=6)$ did not die after surgical resection.

Conclusion: Strong expression of metastin and GPR54 by pancreatic cancer is associated with longer survival. Metastin expression is an independent prognostic factor for the survival of pancreatic cancer patients. The plasma metastin level could become a noninvasive prognostic factor for the assessment of pancreatic cancer. 


\section{Background}

Pancreatic cancer remains a lethal disease and is the fourth to fifth leading cause of cancer-related death in the Western world, despite a significant reduction of the postoperative morbidity and mortality associated with pancreatectomy $[1,2]$. While surgical resection represents the only definitive option for cure of this disease and complete tumor resection is associated with longer survival, only $10 \%$ to $15 \%$ of patients have resectable disease $[3,4]$. Most patients with pancreatic cancer have locally advanced tumors, metastases, or both at the time of diagnosis. In addition, tumors frequently recur, even after margin-free curative resection, and most patients with recurrence have metastasis, which is often fatal. To improve the survival of patients with pancreatic cancer, we need a new strategy for the treatment of advanced disease that is unsuitable for surgical resection.

Metastasis is a multistep process in which tumor cells migrate through the stroma and invade a vessel, after which the cells are transported through the circulation to re-invade and proliferate at a distant site. Dozens of regulators influence each step of the metastatic cascade[5,6]. In 1996, KiSS-1 was identified as a human metastasis-suppressing gene in melanoma cells[7] and breast cancer cells[8]. Then, the KiSS-1 gene product was isolated from human placenta as the endogenous ligand of an orphan G-protein-coupled receptor known as GPR54[9], AXOR12[10], or hOT7T175[11]. KiSS-1 encodes a 145amino acid peptide which is further processed to a C-terminally amidated peptide with 54 amino acids called metastin[11] or kisspeptin-54, as well as to peptides with 14 amino acids (kisspeptin-14) and 13 amino acids (kisspeptin-13)[9].

The bioactive sequence of the KiSS-1 gene product is the C-terminal 10 amino acids, metastin (45-54) (metastin10 or kisspeptin-10)[12]. Metastin was shown to inhibit the chemotaxis and invasion of GPR54-transfected Chinese hamster ovary cells in vitro, while it inhibited the pulmonary metastasis of GPR54-transfected melanoma cells in vivo[11]. The prognostic relevance of KiSS-1 has been demonstrated for some solid tumors [13-21].

In addition to the inhibition of tumor metastasis, KiSS-1 shows neuroendocrine activity and has a role in the gonadotropin-releasing hormone cascade, puberty, placentation, and reproduction, as shown by recent studies[22,23]. In normal tissues, the highest level of KiSS-1 mRNA expression has been detected in the placenta, with moderate to weak expression in the central nervous system, testis, liver, pancreas, and intestine[7,10,11]. In the case of GPR54 mRNA, high levels of expression are found in the placenta, pancreas, and central nervous system [9-11].
We previously found that expression of KiSS-1 mRNA was lower and expression of GPR54 mRNA was higher in pancreatic cancer tissue compared with normal pancreatic tissue[24]. However, the clinical significance of KiSS-1 and GPR54 expression by pancreatic cancer remains unclear. We hypothesized high levels of KiSS-1 and GPR54 expression could be associated with better survival of pancreatic cancer patients. Therefore, we investigated immunohistochemical expression of the KiSS-1 gene product (metastin) and that of GPR54 in pancreatic cancer tissues obtained by surgical resection. We also measured plasma metastin levels in pancreatic cancer patients by using an enzyme immunoassay (EIA) that we previously established[25] and evaluated the clinical applicability of these two parameters.

\section{Methods \\ Patients}

A total of 53 consecutive patients with pancreatic cancer who underwent surgical resection between July 2003 and May 2007 at Kyoto University Hospital were studied. The diagnosis of ductal adenocarcinoma of the pancreas was confirmed histologically by at least two pathologists who examined the resected specimens. None of the patients received preoperative chemotherapy or radiation therapy, and all patients gave written informed consent to participation in the study. Follow-up information was obtained from the medical records or by direct contact with patients or their referring physicians.

We evaluated the following clinicopathological characteristics according to the sixth edition of the TNM classification of the international union against cancer (UICC)[26]: tumor location, tumor size, tumor extent (pT), lymph node metastasis ( $\mathrm{pN})$, pStage, histopathological grade $(\mathrm{G})$, lymphatic invasion, venous invasion, perineural invasion, and residual tumor $(\mathrm{R})$.

\section{Immunohistochemical staining for metastin and GPR54}

Immunohistochemical staining of resected pancreatic tissues was done in 53 patients with ductal adenocarcinoma of the pancreas. We chose sections that contained cancer tissue and adjacent non-cancerous tissue in the same section.

Paraffin-embedded tissue blocks were cut into $4 \mu \mathrm{m}$ sections, dried overnight at $37^{\circ} \mathrm{C}$, and then deparaffinized with xylene and rehydrated in a graded ethanol series. Sections were treated with Dako target retrieval solution (Dako, Carpinteria, CA, USA) before antigen retrieval was done by heating at $95^{\circ} \mathrm{C}$ for $40 \mathrm{~min}$. Then the sections were cooled to room temperature, and were treated with dilute hydrogen peroxide to block endogenous peroxidase activity. Nonspecific binding was minimized by incubation with Dako protein block (Dako) for 30 min. Rabbit 
anti-human polyclonal antibodies for metastin (1-54)Amide (catalogue number: H-048-59, Phoenix Pharmaceuticals, Inc., Burlingame, CA, USA) and GPR54 (375398) (catalogue number: H-048-61, Phoenix Pharmaceuticals) were applied overnight at $4{ }^{\circ} \mathrm{C}$ at a dilution of 1:400. On the next day, sections were incubated for $1 \mathrm{hr}$ at room temperature with anti-rabbit IgG conjugated to a horseradish peroxidase (HRP) -labelled polymer (Dako Envision $^{\mathrm{TM}}+$ System, Dako), treated with 3,3'-diaminobenzidine tetrahydrochloride (DAB), and counterstained with Mayer's hematoxylin. As a positive control, human placental tissue was stained with the anti-metastin and anti-GPR54 antibodies (Figure 1A, 1B). For negative control slides, the primary antibody was substituted with irrelevant rabbit serum.

\section{Assessment of metastin and GPR54 expression}

Five fields (at a $\times 400$ magnification) were randomly chosen to evaluate staining. The intensity of staining in cancer tissues was graded according to a 3-point scale as follows: 0 was weak; 1 was mild (the same staining intensity as that of non-cancerous pancreatic ducts as an internal control on each slide); and 2 was strong. The percentage of tumor cells showing each staining intensity was estimated to calculate an intensity score $([0 \times \%$ weak $]+[1 \times \%$ mild $]+[2$ $\times \%$ strong]) that could range from 0 to 200 . A score $\geq 100$ was defined as positive staining and a score $<100$ was defined as negative staining.

Then we compared clinicopathological characteristics between patients with positive and negative staining for metastin and GPR54.

\section{Blood sampling and EIA for plasma metastin}

Plasma levels of metastin were measured by EIA, as described previously[25], in 23 consecutive patients who underwent resection between July 2006 and May 2007.

A blood sample was collected in the morning before surgery, placed in a chilled tube containing aprotinin (500 $\mathrm{KIU} / \mathrm{ml})$ and EDTA $(1.2 \mathrm{mg} / \mathrm{ml})$, and immediately centrifuged. The plasma thus obtained was diluted five-fold with $4 \%$ acetic acid (pH 4.0), and loaded onto a column with a C18 reversed-phase cartridge (Sep-Pak C18, Millipore, Milford, MA, USA). After washing with $4 \%$ acetic acid, peptides were eluted with $70 \%$ acetonitrile in $0.5 \%$ acetic acid ( $\mathrm{pH} 4.0$ ). The eluted samples were concentrated by spin-vacuum evaporation, lyophilized, and stored at $-40^{\circ} \mathrm{C}$ until assay.

EIA was performed by the delayed-addition method with separation of bound and free antigens on anti-rabbit IgGcoated immunoplates. Human metastin (45-54) was conjugated with $\beta$-D-galactosidase using $N$-( $\varepsilon$-maleimidocaproyloxy)-succinimide, as reported previously[27]. The
EIA was sensitive and specific for all bioactive KiSS-1 gene products (metastin, kisspeptin-14, and kisspeptin13)[25].

The third quartile value was set as a cut-off for the plasma metastin level. We evaluated the association between the plasma level of metastin and metastin immunoreactivity in resected pancreatic cancer tissues, and also the associations between plasma metastin and the clinicopathological characteristics of the patients.

\section{Statistical analysis}

Continuous variables are presented as the mean \pm standard deviation or as the median and range. Comparison of the groups was done with the Mann-Whitney U test, while categorical variables were compared by the $\chi^{2}$ test. Correlations between metastin and GPR54 immunoreactivity were investigated by calculation of Pearson's correlation coefficient $(\mathrm{r})$ values and scatter plots with a linear regression line were drawn. An $r$ value of $0-0.19$ was defined as a very weak correlation, while $0.2-0.39$ was weak, $0.40-$ 0.59 was moderate, $0.6-0.79$ was strong, and $0.8-1$ was very strong. Overall survival curves were drawn by the Kaplan-Meier method, and were compared by the logrank test. Prognostic factors for survival were examined by univariate and multivariate analyses using Cox's proportional hazards model. For all analyses, $\mathrm{p}<0.05$ was considered to be statistically significant.

\section{Results}

\section{Demographic and clinicopathological characteristics}

There were 25 men $(47.2 \%)$ and 28 women $(52.8 \%)$ with a mean age at diagnosis of 65.6 years (median age: 68 years; range: $32-86$ years). The tumor was located in the head of the pancreas in 38 patients $(71.7 \%)$, while it was found in the distal pancreas in 15 patients (28.3\%). Pancreatoduodenectomy was performed in 36 patients (67.9\%), while distal pancreatectomy was performed in 13 patients $(24.5 \%)$, and total pancreatectomy in 4 patients $(7.5 \%)$. On histopathological examination, one patient $(1.9 \%)$ had pStage IA disease, three patients $(5.7 \%)$ had pStage IB, 16 patients $(30.2 \%)$ had pStage IIA, 29 patients $(54.7 \%)$ had pStage IIB, and four patients $(7.5 \%)$ had pStage IV.

Twenty-nine patients received adjuvant chemotherapy, which consisted of S-1 $(n=18)$, gemcitabine $(n=8)$, 5fluorouracil $(n=2)$, and tegafur-uracil $(n=1)$. This was excluded from statistical analysis because of variations in the duration and type of chemotherapy.

\section{Immunostaining for metastin and GPR54}

Pancreatic cancer tissues showed heterogenous immunoreactivity for metastin and GPR54 (Figure 1). Acinar cells and islet cells did not exhibit any immunoreactivity, while 

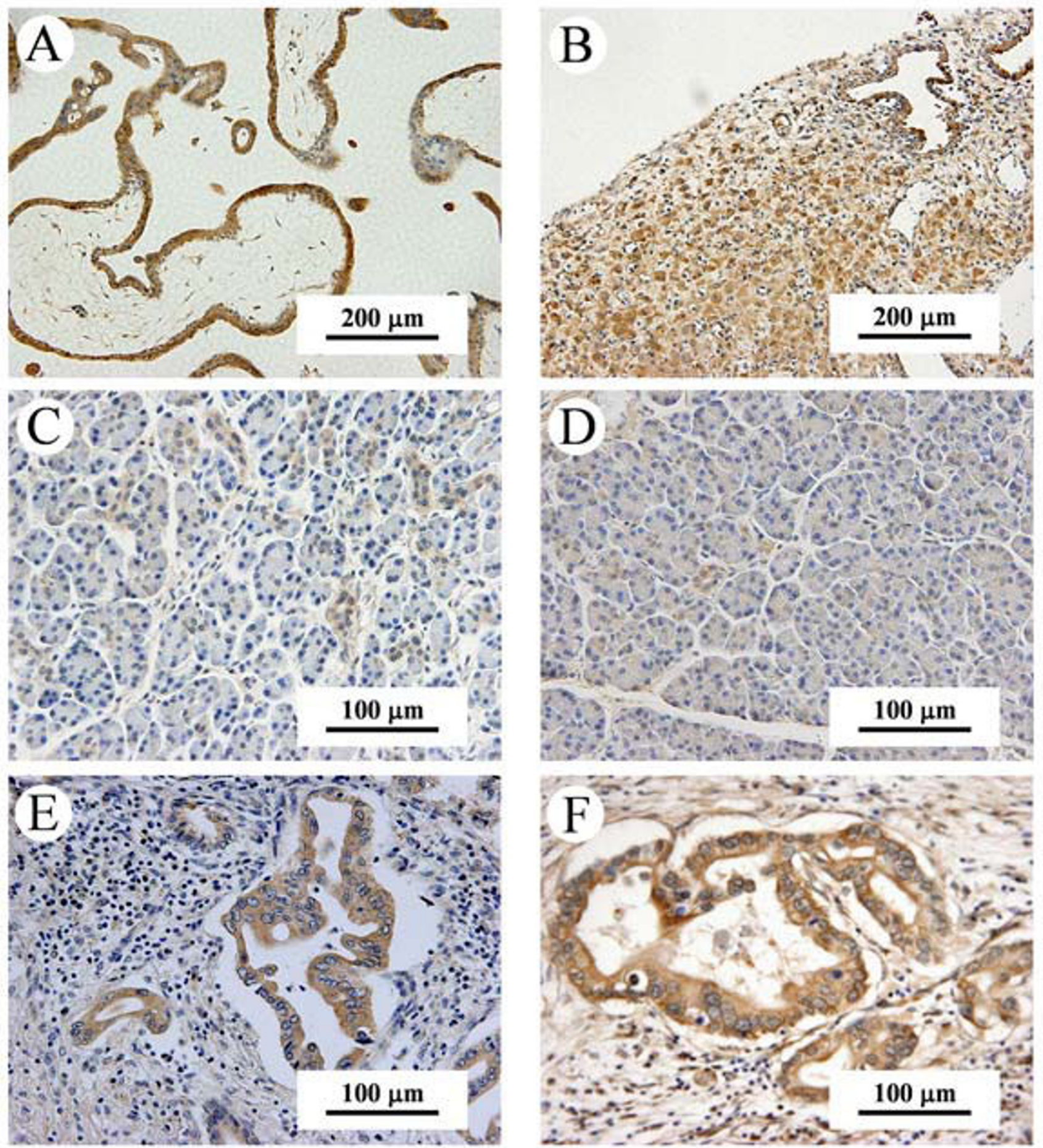

Figure I

Immunohistochemical staining of non-cancerous pancreatic tissues and pancreatic cancer tissues. (A, B); Immunohistochemical staining of human placental tissues as a positive control. Tissues were stained with anti-metastin (A) and antiGPR54 antibody (B). (Original magnification, $\times 200$ ). (C, D); Non-cancerous and cancerous tissues were stained with antimetastin and anti-GPR54 antibody. (Original magnification, $\times 400$ ). Weak positivity of non-cancerous ductal cells for metastin (C) and GPR54 (D). (E, F); Pancreatic cancer tissues were stained with anti-metastin and anti-GPR54 antibody. Heterogeneous strong positive immunostaining of carcinoma cells for metastin (E) and GPR54 (F) are shown. 
metastin and GPR54 were both weak or mildly positive in the cytoplasm of normal pancreatic ductal cells.

The mean intensity score for metastin was $72.1 \pm 54.9$ (n $=53)$ and that for GPR54 was $99.9 \pm 55.1(\mathrm{n}=53)$ (Figure 2).

Positive metastin staining was detected in 13 tumors $(24.5 \%)$, while GPR54 was positive in 30 tumors (56.6\%). Immunoreactivity for metastin and GPR54 showed a strong positive correlation $(\mathrm{r}=0.62$, $\mathrm{p}<0.001$; Fig. 3).

Demographic and clinicopathological characteristics showed no significant differences between patients whose tumors were positive or negative for metastin (Table 1), and the outcome was similar for GPR54 (Table 2). However, tumors that were negative for both metastin and GPR54 showed a significantly larger size than tumors positive for metastin and/or GPR54 (median of $2.5 \mathrm{~cm}$ and range of $0.8-5.0 \mathrm{~cm}$ versus median of $3.0 \mathrm{~cm}$ and range of $1.5-6.5 \mathrm{~cm}, \mathrm{p}=0.047)$.

\section{Recurrence and survival}

The median postoperative follow-up period was 18.5 months (range: 2.6-59.2 months). There were no operative deaths in this series. During the follow-up period, 33 patients $(62.3 \%)$ showed recurrence and 25 patients $(47.2 \%)$ died of their cancer. Recurrence was detected in the liver $(n=15)$, local region $(n=9)$, peritoneum $(n=9)$,

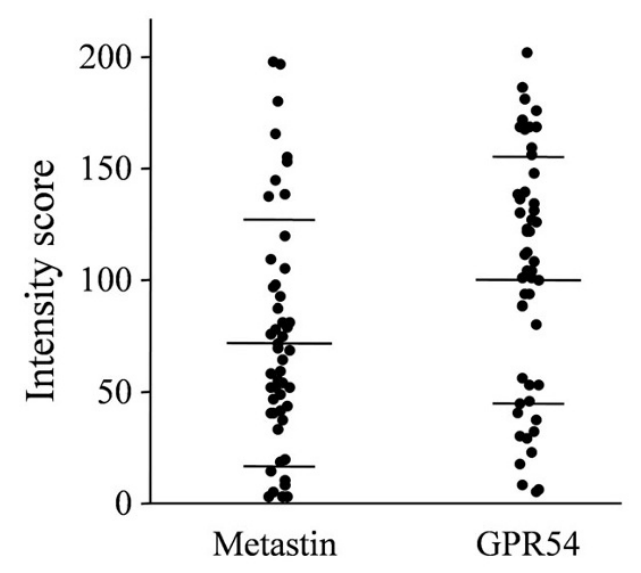

Figure 2

Expression of metastin and GPR54 in pancreatic cancer tissues. Immunoreactivity for metastin and GPR54 in resected pancreatic cancer tissues $(n=53)$ shown as the intensity score of each patient. The mean metastin intensity score was $72.1 \pm 54.9$ and that for GPR54 was $99.9 \pm 55.1$. The horizontal bar indicates the mean \pm SD.

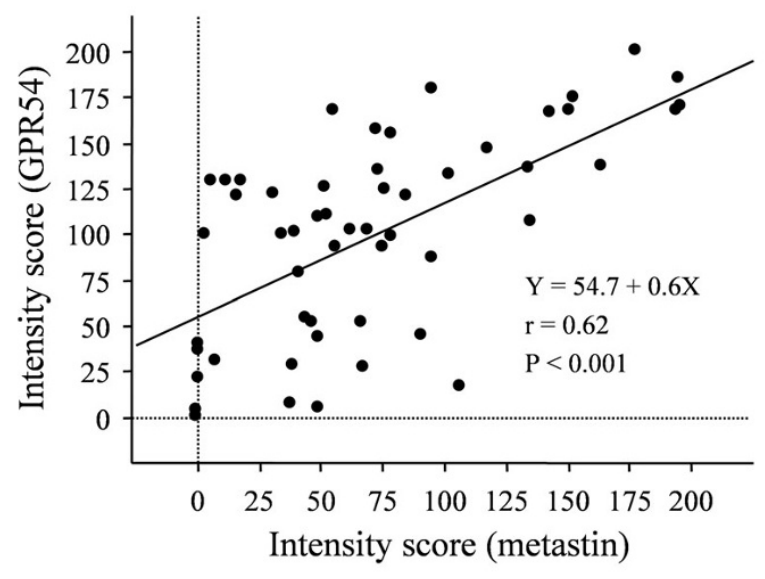

\section{Figure 3}

Correlation between metastin and GPR54 expression in pancreatic cancer tissues. Scatter plot showing the correlation between immunoreactivity for metastin and GPR54. A strong correlation was found $(r=0.62, p<0.001)$.

lymph nodes $(\mathrm{n}=5)$, lungs $(\mathrm{n}=1)$, and bone $(\mathrm{n}=1)$, while it was at an unknown location in 1 patient (elevated tumor marker). No patient died of any other disease or cause.

The recurrence rate was significantly lower in the patients whose tumors were positive for metastin than in those with negative tumors $(38.5 \%$ versus $70.0 \%, \mathrm{p}=0.04$ ) (Table 3). There were no significant differences of the recurrence rate at each site between the patients with metastin-positive and -negative tumors (Table 3), and the same was found for GPR54 (Table 4).

The overall survival of patients whose tumors were positive for metastin was significantly longer than that of patients with negative tumors $(p=0.02)$ (Figure 4$)$. Similarly, the overall survival of patients with tumors that were positive for GPR54 was significantly longer than that of patients with negative tumors $(\mathrm{p}=0.02)$ (Figure 5).

\section{Prognostic factors according to multivariate analysis}

Univariate and multivariate analysis were performed to identify parameters associated with overall survival according to the Cox proportional hazards model. The univariate analysis revealed the following five factors to be associated with survival: perineural invasion, pStage, residual tumor, metastin expression, and GPR54 expression. In the multivariate analysis, as well as the UICC pStage (I + II versus IV), overexpression of metastin was an independent prognostic factor for better survival (hazard ratio, 2.08; 95\% confidence interval, $1.05-4.71 ; \mathrm{p}=0.03$ ) (Table 5). 
Table I: Comparison of the patients with pancreatic cancer who had positive immunostaining for metastin and those negative.

\begin{tabular}{|c|c|c|c|}
\hline Characteristics & $\begin{array}{l}\text { Positive for metastin } \\
\qquad(\mathrm{n}=13)\end{array}$ & $\begin{array}{l}\text { Negative for metastin } \\
\qquad(\mathrm{n}=40)\end{array}$ & $P$ value \\
\hline Age & $68.8 \pm 7.2(71,56-78)$ & $64.5 \pm 10.5(65.5,32-86)$ & 0.19 \\
\hline \multicolumn{4}{|l|}{ Gender } \\
\hline Male & 6 & 19 & 0.93 \\
\hline Female & 7 & 21 & \\
\hline \multicolumn{4}{|l|}{ Location of tumor } \\
\hline Pancreas head & 8 & 30 & 0.35 \\
\hline Pancreas body-tail & 5 & 10 & \\
\hline Size of tumor, $\mathrm{cm}$ & $2.5 \pm 0.9(2.5,1.2-4.5)$ & $3.0 \pm 1.2(2.8,0.8-6.5)$ & 0.34 \\
\hline \multicolumn{4}{|c|}{ Histopathological grading } \\
\hline GI & 5 & 9 & 0.26 \\
\hline G2-4 & 8 & 31 & \\
\hline \multicolumn{4}{|l|}{$\mathrm{pT}$} \\
\hline pTI, pT2 & 2 & 6 & 0.97 \\
\hline PT3 & 11 & 34 & \\
\hline \multicolumn{4}{|l|}{$\mathrm{pN}$} \\
\hline pNo & 6 & 15 & 0.58 \\
\hline $\mathrm{pNI}$ & 7 & 25 & \\
\hline \multicolumn{4}{|l|}{ Lymphatic invasion } \\
\hline Positive & 7 & 24 & 0.70 \\
\hline Negative & 6 & 16 & \\
\hline \multicolumn{4}{|l|}{ Venous invasion } \\
\hline Positive & 7 & 23 & 0.82 \\
\hline Negative & 6 & 17 & \\
\hline \multicolumn{4}{|l|}{ Perineural invasion } \\
\hline Positive & 6 & 22 & 0.58 \\
\hline Negative & 7 & 18 & \\
\hline \multicolumn{4}{|l|}{ pStage } \\
\hline I, II & 13 & 36 & 0.24 \\
\hline IV & 0 & 4 & \\
\hline \multicolumn{4}{|l|}{ Residual tumor } \\
\hline RO & 11 & 28 & 0.30 \\
\hline RI & 2 & 12 & \\
\hline
\end{tabular}

Median and range are shown in parentheses.

\section{Plasma metastin level}

The mean plasma level of metastin before surgery was $22.7 \pm 17.2 \mathrm{fmol} / \mathrm{ml}$ (median, $21.5 \mathrm{fmol} / \mathrm{ml}$; range, 4.0$58.9 \mathrm{fmol} / \mathrm{ml}$ ). Plasma metastin levels and the intensity score for metastin immunoreactivity in resected tissues showed a weak correlation $(\mathrm{r}=0.23, \mathrm{p}=0.30)$. When we used the third quartile plasma metastin level $(28.0 \mathrm{fmol} /$ $\mathrm{ml}$ ) as a cut-off value, there were no significant differences of demographics and clinicopathological characteristics between patients with a high $(n=6)$ or low $(n=17)$ plasma metastin level.

Overall survival curves of the patients with high and low plasma metastin levels are shown in Fig. 6. The median postoperative follow-up period was 14.8 months (range: 2.6-22.1 months, $\mathrm{n}=23$ ). While survival showed no significant difference between the two groups $(\mathrm{p}=0.14)$, no patient with a high plasma metastin levels died after surgery (Figure 6).

\section{Discussion}

In this study, we investigated the clinical significance of immunohistochemical metastin and GPR54 expression in resected pancreatic cancer tissues. We found that strong expression of metastin or GPR54 was associated with better survival, and metastin expression was an independent prognostic factor for longer survival of pancreatic cancer patients. Our results indicate that the metastin/GPR54 signaling system acts to suppress the growth of pancreatic cancer.

Recently, the prognostic relevance of KiSS-1 and GPR54 has been investigated in some solid tumors [13-21]. Most of these studies have shown that the KiSS-1/GPR54 system is negatively correlated with tumor progression. KiSS-1 has been demonstrated to act as a suppressor in melanoma[13], thyroid cancer[14], bladder cancer[16], gastric cancer[17], esophageal cancer[18], and ovarian cancer[20]. 
Table 2: Comparison of the patients with pancreatic cancer who had positive immunostaining for GPR54 and those negative.

\begin{tabular}{|c|c|c|c|}
\hline Characteristics & $\begin{array}{l}\text { Positive for GPR54 } \\
\qquad(\mathrm{n}=30)\end{array}$ & $\begin{array}{l}\text { Negative for GPR54 } \\
\quad(\mathrm{n}=23)\end{array}$ & $P$ value \\
\hline Age & $66.1 \pm 8.7(65.5,49-86)$ & $64.9 \pm 11.5(68.0,32-80)$ & 0.99 \\
\hline \multicolumn{4}{|l|}{ Gender } \\
\hline Male & 12 & 13 & 0.23 \\
\hline Female & 18 & 10 & \\
\hline \multicolumn{4}{|l|}{ Location of tumor } \\
\hline Pancreas head & 21 & 17 & 0.75 \\
\hline Pancreas body-tail & 9 & 6 & \\
\hline Size of tumor, $\mathrm{cm}$ & $2.7 \pm 1.0(2.5,0.8-5.0)$ & $3.1 \pm 1.2(3.0,1.2-6.5)$ & 0.13 \\
\hline \multicolumn{4}{|c|}{ Histolopathological grading } \\
\hline GI & 10 & 4 & 0.19 \\
\hline G2-4 & 20 & 19 & \\
\hline \multicolumn{4}{|l|}{ pT } \\
\hline pTI, pT2 & 6 & 2 & 0.25 \\
\hline PT3 & 24 & 21 & \\
\hline \multicolumn{4}{|l|}{$\mathrm{pN}$} \\
\hline pNo & 13 & 8 & 0.53 \\
\hline $\mathrm{pNI}$ & 17 & 15 & \\
\hline \multicolumn{4}{|l|}{ Lymphatic invasion } \\
\hline Positive & 18 & 13 & 0.80 \\
\hline Negative & 12 & 10 & \\
\hline \multicolumn{4}{|l|}{ Venous invasion } \\
\hline Positive & 18 & 12 & 0.57 \\
\hline Negative & 12 & 11 & \\
\hline \multicolumn{4}{|l|}{ Perineural invasion } \\
\hline Positive & 15 & 13 & 0.64 \\
\hline Negative & 15 & 10 & \\
\hline \multicolumn{4}{|l|}{ pStage } \\
\hline I, II & 29 & 20 & 0.18 \\
\hline IV & 1 & 3 & \\
\hline \multicolumn{4}{|l|}{ Residual tumor } \\
\hline RO & 24 & 15 & 0.23 \\
\hline RI & 6 & 8 & \\
\hline
\end{tabular}

Median and range are shown in parentheses.

For example, Shirasaki et al[13] showed that downregulation of KiSS-1 is important for the progression of melanoma in vivo. Ringel et al[14] showed that KiSS-1 and GPR54 mRNA were overexpressed in papillary thyroid cancer compared with follicular cancer. In bladder cancer, loss of KiSS-1 expression is related to tumor pro- gression[16]. In gastric cancer, lower expression of KiSS-1 mRNA is associated with venous invasion, distant metastasis, and tumor recurrence[17]. Furthermore, KiSS-1 is an independent prognostic marker for gastric cancer according to multivariate analysis [17]. Ikeguchi et al. [18] observed that loss of KiSS-1 mRNA, GPR54 mRNA, or

Table 3: The rate and site of recurrence after resection of pancreatic cancer in relation to metastin expression.

\begin{tabular}{|c|c|c|c|}
\hline & Metastin expression Positive $(n=13)$ & Metastin expression Negative $(n=40)$ & $P$ value \\
\hline Recurrence, n (\%) & $5(38.5 \%)$ & $28(70.0 \%)$ & 0.04 \\
\hline \multicolumn{4}{|l|}{ Site of recurrence } \\
\hline Liver, n (\%) & $4(30.8 \%)$ & II (27.5\%) & 0.82 \\
\hline Local, n (\%) & $2(15.4 \%)$ & 7 (I7.5\%) & 0.86 \\
\hline Peritoneum, n (\%) & I $(7.7 \%)$ & $8(20.0 \%)$ & 0.30 \\
\hline Lymph nodes, n (\%) & I (7.7\%) & $4(10.0 \%)$ & 0.80 \\
\hline Lungs, $n(\%)$ & 0 & I $(2.5 \%)$ & 0.56 \\
\hline Bone, n (\%) & 0 & I $(2.5 \%)$ & 0.56 \\
\hline Unknown*, n (\%) & 0 & $\mathrm{I}(2.5 \%)$ & 0.56 \\
\hline
\end{tabular}

* Confirmed by elevated tumor marker during follow-up 
Table 4: The rate and site of recurrence after resection of pancreatic cancer in relation to GPR54 expression.

\begin{tabular}{|c|c|c|c|}
\hline & GPR54 expression Positive $(n=30)$ & GPR54 expression Negative $(n=23)$ & $P$ value \\
\hline Recurrence, n (\%) & $17(56.7 \%)$ & $16(69.6 \%)$ & 0.34 \\
\hline \multicolumn{4}{|l|}{ Site of recurrence } \\
\hline Liver, n (\%) & $8(26.7 \%)$ & $7(30.4 \%)$ & 0.76 \\
\hline Local, n (\%) & $6(20.0 \%)$ & $3(13.0 \%)$ & 0.50 \\
\hline Peritoneum, n (\%) & $5(16.7 \%)$ & 4 (17.4\%) & 0.95 \\
\hline Lymph nodes, n (\%) & $2(6.7 \%)$ & $3(13.0 \%)$ & 0.43 \\
\hline Lungs, n (\%) & I (3.3\%) & 0 & 0.38 \\
\hline Bone, $n(\%)$ & 0 & I (4.3\%) & 0.25 \\
\hline Unknown*, n (\%) & 0 & I (4.3\%) & 0.25 \\
\hline
\end{tabular}

* Confirmed by elevated tumor marker during follow-up

both in esophageal squamous cell carcinoma was a significant predictor of lymph node metastasis. Finally, the survival of ovarian cancer patients with low GPR54 mRNA expression is significantly worse than that of those with high expression[20].

On the other hand, studies in patients with breast cancer[19] and hepatocellular carcinoma (HCC) [15,21] have yielded opposite results, with a positive association between increased KiSS-1 levels and disease progression. Martin et al. [19] found that KiSS-1 mRNA expression was increased in aggressive breast cancer. Ikeguchi et al. [15] reported that overexpression of KiSS-1 and GPR54 was correlated with the progression of HCC. Schmid et al. [21] performed an immunohistochemical study and concluded that high KiSS-1 expression was an independent

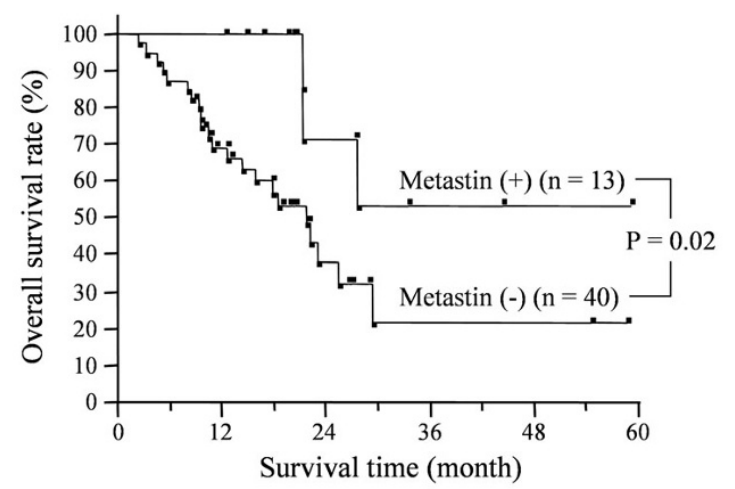

Figure 4

Impact of metastin expression on survival time of pancreatic cancer patients. Overall survival of patients whose tumors were positive $(n=13)$ or negative $(n=40)$ for metastin immunostaining. The survival of patients with positive tumors was significantly longer than that of patients with negative tumors $(p=0.02)$. prognostic factor for shorter survival of patients with HCC.

The mechanism by which the KiSS-1/GPR54 system regulates tumor progression still remains unclear, although various studies have revealed the downstream signaling pathways activated by KiSS-1 gene product. This might indicate that a complex signaling network exists with diverse physiological responses $[23,28]$.

Stafford et al. [29] found that binding of KiSS-1 peptide to the receptor leads to activation of G-protein-activated phospholipase $\mathrm{C}$, which suggested a direct relation of KiSS-1 to the Gaq-mediated phospholipase C-Ca ${ }^{2+}$ signaling pathway. In addition, activation of GPR54 has been shown to cause an increase of intracellular calcium [9-11],

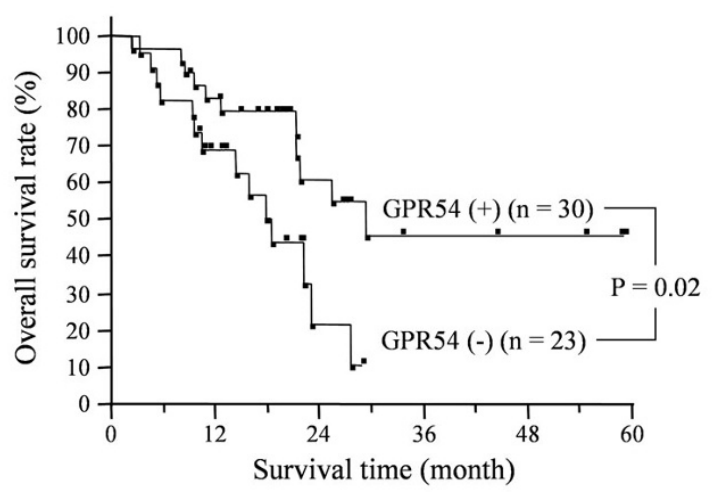

Figure 5

Impact of GPR54 expression on survival time of pancreatic cancer patients. Overall survival of patients whose tumors were positive $(n=30)$ or negative $(n=23)$ for GPR54 immunostaining. The survival of patients with tumors positive for GPR54 was significantly longer than that of those with negative tumors $(p=0.02)$. 
Table 5: Univariate and Multivariate analyses of factors associated with survival after resection in patients with pancreatic cancer.

\begin{tabular}{|c|c|c|c|c|}
\hline \multirow[b]{2}{*}{ Characteristics } & \multicolumn{2}{|c|}{ Univariate analysis } & \multicolumn{2}{|c|}{ Multivariate analysis } \\
\hline & Hazard ratio $(95 \% \mathrm{Cl})$ & $P$ value & Hazard ratio $(95 \% \mathrm{Cl})$ & $P$ value \\
\hline Age (continuous variables) & $1.01(0.97-I .1)$ & 0.50 & $1.03(0.97-1.1)$ & 0.29 \\
\hline Gender (male versus female) & $1.09(0.73-1.6)$ & 0.66 & $1.16(0.73-1.9)$ & 0.52 \\
\hline Location of tumor (head versus body-tail) & $1.08(0.72-1.7)$ & 0.72 & $0.71(0.40-1.3)$ & 0.25 \\
\hline Size of tumor (continuous variables) & $1.01(0.97-1.0)$ & 0.63 & $1.01(0.96-1.1)$ & 0.69 \\
\hline Histopathological grading (GI versus G2-4) & $\mathrm{I} .05(0.70-\mathrm{I} .7)$ & 0.80 & $0.92(0.49-1.8)$ & 0.79 \\
\hline pT (pTI, pT2 versus pT3) & $1.62(0.88-4.0)$ & 0.14 & $2.07(0.86-6.7)$ & 0.11 \\
\hline $\mathrm{pN}(\mathrm{pN} 0$ versus $\mathrm{pNI})$ & $1.27(0.85-2.0)$ & 0.25 & $1.01(0.58-1.8)$ & 0.97 \\
\hline Lymphatic invasion (positive versus negative) & $1.20(0.80-1.8)$ & 0.33 & $0.97(0.54-1.7)$ & 0.92 \\
\hline Venous invasion (positive versus negative) & $1.01(0.68-1.5)$ & 0.95 & $0.91(0.52-1.6)$ & 0.73 \\
\hline Perineural invasion (positive versus negative) & $1.57(1.1-2.4)$ & 0.03 & $1.47(0.85-2.7)$ & 0.17 \\
\hline pStage (I, II versus IV) & $3.16(1.6-5.8)$ & 0.002 & $2.70(1.1-6.8)$ & 0.03 \\
\hline Residual tumor (R0 versus RI) & $1.61(1.0-2.5)$ & 0.03 & $1.60(0.91-2.9)$ & 0.10 \\
\hline Metastin expression (positive versus negative) & $1.93(1.1-4.0)$ & 0.01 & $2.08(1.1-4.7)$ & 0.03 \\
\hline GPR54 expression (positive versus negative) & $1.62(1.1-2.5)$ & 0.02 & $1.22(0.74-2.0)$ & 0.43 \\
\hline
\end{tabular}

arachidonic acid release [9], activation of mitogen-activated protein kinases (MAPKs), and activation of extracellular signal-regulated kinase (ERK) $1 / 2[9,14]$. We have observed that exogenous metastin reduces migration of pancreatic cancer cells, while it induces the activation of ERK1 and p38[24]. Furthermore, the KiSS-1 product was shown to repress $92-\mathrm{kDa}$ type 4 collagenase and matrix metalloproteinase (MMP)-9 expression by decreasing the binding of NF-אB to the promoter [30]. Bilban et al. [31]

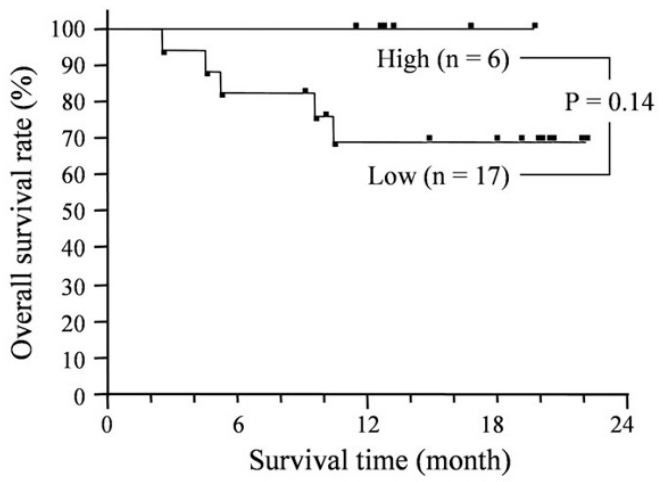

Figure 6

Impact of plasma metastin levels on survival time of pancreatic cancer patients. Overall survival of patients with high $(n=6)$ and low $(n=17)$ plasma metastin levels. There was no significant difference between the two groups $(p=0.14)$, but no patient with a high plasma metastin level died after surgery. also found downregulation of MMP-2 activity by the KiSS1 gene product in human trophoblasts, which implies an association between the tumor suppressor role of KiSS-1 suggested in this study and our previous report that activation of MMP-2 has a significant role in invasion and metastasis of pancreatic cancer[32].

KiSS-1 has also been shown to influence cell adhesion by forming focal adhesions through phosphorylation of focal adhesion kinase and paxillin [11], and an association between loss of KiSS-1 expression and E-cadherin expression was reported in bladder cancer [16].

In our series, there were no significant differences of clinicopathological characteristics between the patients whose tumors showed positive and negative metastin immunostaining, and the result was similar for GPR54. On the other hand, patients whose tumors showed negative immunoreactivity for both metastin and GPR54 had significantly larger tumors than those with lesions positive for either molecule. In addition, recurrence was more frequent in the patients with metastin-negative tumors than in those with metastin-positive tumors. These results suggest that pancreatic cancer loses metastin and GPR54 expression along with its progression. The KiSS-1 gene is mapped to chromosome 1q32-q41 [33] and KiSS-1 expression is regulated by genes located on chromosome 6 within the region $6 q 16.3-q 23[13,28]$. These findings are consistent with the fact that loss of $6 \mathrm{q}, 8 \mathrm{p}, 9 \mathrm{p}, 12 \mathrm{q}$, $17 \mathrm{p}$, and $18 \mathrm{q}$ is frequently observed in pancreatic cancer[34,35].

Finally, we measured the plasma metastin level in 23 of our patients with pancreatic cancer. We previously found 
that the plasma metastin level of patients with pancreatic cancer is significantly higher than that of age- and gendermatched healthy volunteers (unpublished data), so we considered that there was potential to use plasma metastin as a novel tumor marker. In the present series, there was no significant difference of survival between the patients with high and low plasma metastin levels, but no patient with a high plasma metastin level died after surgery. Since the number of patients and the follow-up period are insufficient, more data and further investigation will be needed to clarify the value of measuring plasma metastin.

In this study, the plasma metastin level and metastin immunoreactivity in resected tumor tissues showed a weak correlation. It would be clinically useful if plasma metastin levels had prognostic significance because metastin expression in resected tumor tissues was shown to be a prognostic factor in this study.

\section{Conclusion}

In conclusion, expression of metastin and GPR54 was associated with better survival of patients with pancreatic cancer. Metastin expression by cancer tissue was an independent prognostic factor for better survival. Furthermore, the serum metastin level could become a noninvasive prognostic tool for patients with pancreatic cancer.

\section{Competing interests}

The authors declare that they have no competing interests.

\section{Authors' contributions}

KN conceived of the study and performed immunohistochemical studies and measurements of serum metastin. $\mathrm{RD}$ conceived of the study, and participated in its design and coordination and helped to draft the manuscript. FK and TI conceived of the study and performed immunohistochemical studies. AK and MK conceived of the study and performed measurements of serum meatstin. TM, YK, KT, SO and NF conceived of the study and performed experiments on pancreatic cancer tissues. SU conceived of the study, and participated in its design.

\section{Acknowledgements}

This study was supported by a Grant-in-Aid (\#20390355) from the Ministry of Education, Culture, Sports, Science and Technology.

\section{References}

I. Jemal A, Thomas A, Murray T, Thun M: Cancer statistics, 2002. CA Cancer I Clin 2002, 52:23-47.

2. Jemal A, Siegel R, Ward E, Hao Y, Xu J, Murray T, Thun MJ: Cancer statistics, 2008. CA Cancer J Clin 2008, 58:7l-96.

3. Sener SF, Fremgen A, Menck HR, Winchester DP: Pancreatic cancer: a report of treatment and survival trends for 100,313 patients diagnosed from I985-1995, using the National Cancer Database. J Am Coll Surg 1999, 189:1-7.
4. Schneider G, Siveke IT, Eckel F, Schmid RM: Pancreatic cancer: basic and clinical aspects. Gastroenterology 2005, I 28: I606-I 625. 5. Hezel AF, Kimmelman AC, Stanger BZ, Bardeesy N, Depinho RA: Genetics and biology of pancreatic ductal adenocarcinoma. Genes Dev 2006, 20:1218-1249.

6. Stafford LJ, Vaidya KS, Welch DR: Metastasis suppressors genes in cancer. Int J Biochem Cell Biol 2008, 40:874-89I.

7. Lee JH, Miele ME, Hicks DJ, Phillips KK, Trent JM, Weissman BE, Welch DR: KiSS-I, a novel human malignant melanoma metastasis-suppressor gene. J Natl Cancer Inst 1996, 88: $1731-1737$.

8. Lee JH, Welch DR: Suppression of metastasis in human breast carcinoma MDA-MB-435 cells after transfection with the metastasis suppressor gene, KiSS-I. Cancer Res 1997, 57:2384-2387.

9. Kotani M, Detheux M, Vandenbogaerde A, Communi D, Vanderwinden JM, Le Poul E, Brezillon S, Tyldesley R, Suarez-Huerta N, Vandeput F, Blanpain C, Schiffmann SN, Vassart G, Parmentier M: The metastasis suppressor gene KiSS-I encodes kisspeptins, the natural ligands of the orphan $\mathbf{G}$ protein-coupled receptor GPR54. J Biol Chem 200I, 276:3463I-34636.

10. Muir AI, Chamberlain L, Elshourbagy NA, Michalovich D, Moore DJ, Calamari A, Szekeres PG, Sarau HM, Chambers JK, Murdock P, Steplewski K, Shabon U, Miller JE, Middleton SE, Darker JG, Larminie CG, Wilson S, Bergsma DJ, Emson P, Faull R, Philpott KL, Harrison DC: AXORI2, a novel human $G$ protein-coupled receptor, activated by the peptide KiSS-I. J Biol Chem 200I, 276:28969-28975.

II. Ohtaki T, Shintani Y, Honda S, Matsumoto H, Hori A, Kanehashi K, Terao Y, Kumano S, Takatsu Y, Masuda Y, Ishibashi Y, Watanabe T, Asada M, Yamada T, Suenaga M, Kitada C, Usuki S, Kurokawa T, Onda $\mathrm{H}$, Nishimura O, Fujino M: Metastasis suppressor gene KiSS-I encodes peptide ligand of a G-protein-coupled receptor. Nature 2001, 41 I:613-617.

12. Niida A, Wang Z, Tomita K, Oishi S, Tamamura H, Otaka A, Navenot JM, Broach JR, Peiper SC, Fujii N: Design and synthesis of downsized metastin (45-54) analogs with maintenance of high GPR54 agonistic activity. Bioorg Med Chem Lett 2006, I 6: I 34- I 37.

13. Shirasaki F, Takata M, Hatta N, Takehara K: Loss of expression of the metastasis suppressor gene KiSSI during melanoma progression and its association with LOH of chromosome 6q 16.3-q23. Cancer Res 200I, 6 I:7422-7425.

14. Ringel MD, Hardy E, Bernet VJ, Burch HB, Schuppert F, Burman KD, Saji $M$ : Metastin receptor is overexpressed in papillary thyroid cancer and activates MAP kinase in thyroid cancer cells. J Clin Endocrinol Metab 2002, 87:2399.

15. Ikeguchi M, Hirooka Y, Kaibara N: Quantitative reverse transcriptase polymerase chain reaction analysis for KiSS-I and orphan G-protein-coupled receptor (hOT7TI75) gene expression in hepatocellular carcinoma. J Cancer Res Clin Oncol 2003, I 29:53|-535.

16. Sanchez-Carbayo M, Capodieci P, Cordon-Cardo C: Tumor suppressor role of KiSS-I in bladder cancer: loss of KiSS-I expression is associated with bladder cancer progression and clinical outcome. Am J Pathol 2003, I 62:609-6I7.

17. Dhar DK, Naora H, Kubota H, Maruyama R, Yoshimura H, Tonomoto $Y$, Tachibana M, Ono T, Otani H, Nagasue N: Downregulation of KiSS-I expression is responsible for tumor invasion and worse prognosis in gastric carcinoma. Int J Cancer 2004, I I I :868-872.

18. Ikeguchi M, Yamaguchi K, Kaibara N: Clinical significance of the loss of KiSS-I and orphan G-protein-coupled receptor (hOT7TI75) gene expression in esophageal squamous cell carcinoma. Clin Cancer Res 2004, 10:1379-1383.

19. Martin TA, Watkins G, Jiang WG: KiSS-I expression in human breast cancer. Clin Exp Metastasis 2005, 22:503-5 I I.

20. Hata K, Dhar DK, Watanabe $Y$, Nakai H, Hoshiai H: Expression of metastin and a G-protein-coupled receptor (AXORI2) in epithelial ovarian cancer. Eur J Cancer 2007, 43: I 452-I459.

21. Schmid K, Wang X, Haitel A, Sieghart W, Peck-Radosavljevic M, Bodingbauer M, Rasoul-Rockenschaub S, Wrba F: KiSS-I overexpression as an independent prognostic marker in hepatocellular carcinoma: an immunohistochemical study. Virchows Arch 2007, 450: |43-I49. 
22. Dhillo WS, Murphy KG, Bloom SR: The neuroendocrine physiology of kisspeptin in the human. Rev Endocr Metab Disord 2007, 8:41-46.

23. Mead EJ, Maguire JJ, Kuc RE, Davenport AP: Kisspeptins: a multifunctional peptide system with a role in reproduction, cancer and the cardiovascular system. Br J Pharmacol 2007, I5 I:I |43-II53.

24. Masui T, Doi R, Mori T, Toyoda E, Koizumi M, Kami K, Ito D, Peiper SC, Broach JR, Oishi S, Niida A, Fujii N, Imamura M: Metastin and its variant forms suppress migration of pancreatic cancer cells. Biochem Biophys Res Commun 2004, 3 I 5:85-92.

25. Katagiri F, Tomita K, Oishi S, Takeyama M, Fujii N: Establishment and clinical application of enzyme immunoassays for determination of luteinizing hormone releasing hormone and metastin. J Pept Sci 2007, 13:422-429.

26. International Union Against Cancer (UICC): TNM Classification of Malignant Tumours 6th edition. New York: Wiley-Liss; 2002.

27. Kitagawa T, Shimozono T, Aikawa T, Yoshida T, Nishimura H: Preparation and characterization of hetero-bifunctional crosslinking reagents for protein modifications. Chem Pharm Bull 1981, 29: II30-II35.

28. Harms JF, Welch DR, Miele ME: KISSI metastasis suppression and emergent pathways. Clin Exp Metastasis 2003, 20: II-18.

29. Stafford LJ, Xia C, Ma W, Cai Y, Liu M: Identification and characterization of mouse metastasis-suppressor KiSSI and its Gprotein-coupled receptor. Cancer Res 2002, 62:5399-5404.

30. Yan C, Wang H, Boyd DD: KiSS-I represses 92-kDa type IV collagenase expression by down-regulating NF-kappa B binding to the promoter as a consequence of lkappa Balpha -induced block of p65/p50 nuclear translocation. J Biol Chem 200I, 276: II64-II72.

31. Bilban M, Ghaffari-Tabrizi N, Hintermann E, Bauer S, Molzer S, Zoratti C, Malli R, Sharabi A, Hiden U, Graier W, Knofler M, Andreae F, Wagner O, Quaranta V, Desoye G: Kisspeptin- I0, a KiSS- I/metastinderived decapeptide, is a physiological invasion inhibitor of primary human trophoblasts. J Cell Sci 2004, I 17:1319-1328.

32. Koshiba T, Hosotani R, Wada M, Miyamoto Y, Fujimoto K, Lee JU, Doi R, Arii S, Imamura M: Involvement of matrix metalloproteinase-2 activity in invasion and metastasis of pancreatic carcinoma. Cancer 1998, 82:642-650.

33. West A, Vojta PJ, Welch DR, Weissman BE: Chromosome localization and genomic structure of the KiSS-I metastasis suppressor gene (KISSI). Genomics 1998, 54: I45-I 48.

34. Yatsuoka T, Sunamura M, Furukawa T, Fukushige S, Yokoyama T, Inoue H, Shibuya K, Takeda K, Matsuno S, Horii A: Association of poor prognosis with loss of $12 q, 17 p$, and $18 q$, and concordant loss of $6 q / 17 p$ and $/ 2 q / 18 q$ in human pancreatic ductal adenocarcinoma. Am J Gastroenterol 2000, 95:2080-2085.

35. Harada T, Okita K, Shiraishi K, Kusano N, Furuya T, Oga A, Kawauchi $\mathrm{S}$, Kondoh S, Sasaki K: Detection of genetic alterations in pancreatic cancers by comparative genomic hybridization coupled with tissue microdissection and degenerate oligonucleotide primed polymerase chain reaction. Oncology 2002, 62:25I-258.
Publish with Biomed Central and every scientist can read your work free of charge

"BioMed Central will be the most significant development for disseminating the results of biomedical research in our lifetime. "

Sir Paul Nurse, Cancer Research UK

Your research papers will be:

- available free of charge to the entire biomedical community

- peer reviewed and published immediately upon acceptance

- cited in PubMed and archived on PubMed Central

- yours - you keep the copyright
BioMedcentral 